\title{
Crescimento inicial e resposta estomática de milho pipoca sob estresse salino
}

Rayane Monique Sete da Cruz, Renan Almeida De Jesus, Meire Pereira Ferrari de Souza, Caroline Cagnini, Giuliana Zardeto Sabec, Thais Lorana Savoldi, Silvia Graciele Hulse de Souza

Universidade Paranaense - UNIPAR, Biotecnologia aplicada a agricultura. E-mail: silviahulse@prof.unipar.br

\section{Resumo}

A salinidade se destaca como um problema de grande importância, pois pode limitar o desenvolvimento e a produção agrícola. $O$ estresse salino em plantas pode afetar o seu metabolismo, além de estimular o acúmulo de osmólitos. Portanto, o objetivo desse trabalho foi avaliar o crescimento, mudanças fisiológicas e estomáticas de plantas de milho pipoca submetidas ao estresse salino. $O$ experimento foi inteiramente casualizado, com 6 vasos por tratamento, conduzido em câmera de crescimento e irrigadas com $\mathrm{NaCl}$ nas concentrações de 0, 100 e $200 \mathrm{mM}$ por 15 dias. As concentrações de $100 \mathrm{mM}$ e $200 \mathrm{mM}$ de $\mathrm{NaCl}$, ocasionaram reduções significavas na altura e massa fresca da parte aérea e raízes. Observamos um aumento do dano na membrana plasmática e consequentemente uma redução no teor relativo de água nas folhas, devido às mudanças ocorridas na atividade osmótica. Além disso, houve o acúmulo de prolina, aumento no teor de clorofila e um aumento significativo no número de estômatos na superfície abaxial, assim como uma redução do tamanho dos estômatos. As plantas apresentaram um conjunto de alterações morfológicas e fisiológicas que são um mecanismo de defesa contra os efeitos da salinidade. Nossos resultados demonstraram que essas características contribuíram para uma notável tolerância à salinidade, pois possuem um importante papel protetor contra os diferentes estresses ambientais.

Palavras-chave: adaptações estomáticas; estresse ambiental; tolerância; salinidade; Zea mays everta.

\section{Initial growth and stomatal response of popcorn (Zea mays everta) under salt stress}

\begin{abstract}
Salinity stands out as a major problem environmental that it may limit agricultural development and productivity. Saline stress in plants can affect your metabolism, in addition to stimulating the accumulation of osmolytes. Therefore, the aim is study was to evaluate the growth and extend our understanding physiological and stomatal changes in popcorn plants submitted to salinity stress. The experiment was completely randomized, with 6 pots per treatment, conducted in a growth chamber and irrigated with $\mathrm{NaCl}$ at the concentrations 0,100 and $200 \mathrm{mM}$ for 15 days. 100 and $200 \mathrm{mM} \mathrm{NaCl}$ concentrations cause significant reductions in height and fresh mass of shoots and roots. We observe an increase in the plasma membrane damage and consequently a reduction in relative water content in the leaves due to changes in the osmotic activity. Accordingly, an involvement there was a proline accumulation, increase in chlorophyll content and a significant increase in a number of stomata on abaxial surface, as well as a reduction in the size of the stomata. Plants presented a set of morphological and physiological changes, triggering a defense mechanism against the effects of salinity. Finally, our results demonstrated that these characteristics contributed to a remarkable tolerance to salinity since they have an important protective role against the different environmental stresses.
\end{abstract}

Keywords: stomatal adaptations; environmental stress; tolerance, salinity; Zea mays everta.

\section{Introdução}

O milho pipoca (Zea mays L. everta) é um milho especial, pertencente a ordem Poales, família das Poaceae e tribo Maydeae, no qual é caracterizado por possuir grãos pequenos e duros que têm a capacidade de estourar quando aquecidos em torno de $180 \stackrel{\circ}{\circ}$ diferenciando-se deste modo do milho comum (ORTEGA, 2014; 
SOUZA et al., 2014; OLIVEIRA et al., 2016). O Brasil é o segundo maior produtor de milho pipoca do mundo, com produção de $80 \mathrm{mil}$ toneladas ao ano (MIRANDA et al., 2011). O mercado mundial de milho pipoca deve crescer 7,52\% no período 2017-2023. O mercado global de pipoca foi avaliado em US\$ 9.060 milhões em 2016 e está projetado para atingir US\$ 15.098 milhões até 2023 (DAWANDE, 2018).

Sua época de plantio se dá em período chuvoso, ou sob condições climáticas que possibilitem o cultivo irrigado (SOUZA et al., 2014). O território nacional possui grandes áreas áridas e semiáridas, onde o índice de precipitação é inferior a evaporação, causando enormes prejuízos a produção agrícola. O manejo inadequado da irrigação e a existência de elevada evapotranspiração e de precipitações insuficientes para percolar os sais do solo contribuem para o acúmulo destes, causando a salinização das áreas irrigadas (SILVA et al., 2017). A salinidade se destaca como um problema de grande importância que pode limitar $o$ desenvolvimento e a produção dos mais diversos cultivares (JIANG et al., 2017; KONUŞKAN et al., 2017). A inibição do crescimento da planta sob o efeito do estresse salino pode ocorrer pelo efeito osmótico que reduz a absorção de água, ou pelo excesso de íns que entram nas vias de transporte por meio da transpiração, reduzindo a absorção de elementos essenciais e causando danos morfológicos a planta (MUNNS; GILLIHAM, 2015).

Vários estudos apontam a influência negativa da salinidade excessiva do solo. Souza et al. (2014), constataram que o desenvolvimento inicial do milho doce e milho pipoca foi afetado pelo aumento da salinidade da água de irrigação sendo as variáveis mais afetadas a massa seca de pendão, massa seca de folhas, massa seca de raiz e massa seca de total. Resultados semelhantes foram verificados por Sousa et al. (2012) para a matéria seca da parte aérea e da raiz e matéria seca total das plantas de milho Zea mays L. submetidas a estresse salino.

Silva et al. (2017) verificaram que a concentração salina interferiu negativamente de maneira gradual a altura e o diâmetro de milho AG1051. Não obstante, estudos anteriores realizados por Sousa et al. (2012) e Oliveira et al. (2009), também verificaram esse efeito negativo no desenvolvimento da parte aérea de milho com altos teores de salinidade. Além disso, Molazem e Azimi (2015) verificaram que os genótipos de milho avaliados podem responder de formas diferentes ao excesso de sol no solo.

Pesquisas afirmam que a intensidade do efeito da salinidade sobre o desenvolvimento das plantas é variável em função do órgão analisado. $\mathrm{E}$ que nem todas as partes da planta são igualmente afetadas pela salinidade, a adaptação ao estresse salino também varia entre espécies e em um mesmo genótipo pode variar entre estádios fenológicos (MORALES et al., 2001; SOUZA et al., 2014).

No entanto, na tentativa de conter o estresse salino as plantas acionam mecanismos de defesa. Sendo o ajuste osmótico um dos mecanismos fisiológicos mais eficazes para manutenção da homeostase celular (MARIJUAN; $\mathrm{BOSCH}, 2013)$. Várias são as estruturas ligadas a esses mecanismos, sendo os estômatos uma das principais vias de ativação no processo de defesa de plantas, a diminuição da abertura estomática inibe a fotossíntese, minimizando a perda de água pela restrição da condução de $\mathrm{CO}_{2}$ (ESTEVES; SUZUKI, 2008). Além disso, modificações anatômicas como espessamento da folha, aumento da espessura epidérmica, presença de cutícula na superfície da folha e alterações na distribuição e tamanho dos estômatos (DOUPIS et al., 2016).

A disponibilidade de solutos compatíveis como a prolina têm função osmoprotetora contra subprodutos tóxicos do metabolismo, resultantes do estresse, contribuindo também para a manutenção do equilíbrio hídrico e a preservação da integridade de proteínas, enzimas e membranas celulares (ESTEVES; SUZUKI, 2008, ASHRAF et al., 2011; MARIJUAN; BOSCH, 2013; REDDY et al., 2015; PERVEEN; NAZIR, 2018). Vários estudos apontam 0 aumento do aminoácido prolina em folhas de plantas submetidos ao estresse salino (SILVA et al., 2009; MARIJUAN; BOSCH, 2013; NEVES; SPAT, 2013).

Diante desse contexto e da falta de informações sobre o crescimento inicial e características estomáticas em Zea mays everta submetido ao estresse salino, este trabalho teve como objetivo avaliar o crescimento, as mudanças fisiológicas e estomáticas de milho pipoca submetidos a diferentes níveis de salinidade.

\section{Material e Métodos \\ Material vegetal}

O experimento foi realizado no

Laboratório de Cultura de Tecidos da 
Universidade Paranaense - UNIPAR, Umuarama/PR. Foram utilizadas sementes de milho pipoca genótipo UENF-14 e semeadas em substrato comercial (Carolina Padrão ${ }^{\circledR}$ ), com cinco sementes por vaso. Após cinco dias foi realizado o desbaste deixando 2 plantas por vaso. Foram utilizados 6 vasos por tratamento em um delineamento inteiramente casualizado (DIC). O experimento foi conduzido em câmara de crescimento $25 \pm 2 \circ \mathrm{C}$, intensidade luminosa com aproximadamente $200 \mu \mathrm{mol} \mathrm{m} \mathrm{m}^{-2} \mathrm{~s}^{-1}$, umidade relativa $60 \pm 5 \%$. As plântulas foram irrigadas diariamente com solução de $\mathrm{NaCl}$ nas concentrações de 0 mM, 100 mM e 200 mM e duas vezes por semana com solução nutritiva de Hoagland e Arnon (1950). Para evitar o choque osmótico a irrigação com a solução de $\mathrm{NaCl}$ foi aumentada de forma gradativa, no qual a cada dia de irrigação houve um aumento de $50 \mathrm{mM}$ de acordo com a concentração de cada um dos tratamentos. As plantas foram coletadas após 15 dias de estresse e armazenadas em ultrafreezer 80 으.

\section{Comprimento e massa fresca da parte aérea e raiz}

A determinação do comprimento da parte aérea (CPA) e da raiz (CRA) foi realizada com o auxílio de uma fita métrica do colo da planta até o seu ápice foliar e expressa em centímetros $(\mathrm{cm})$. A massa fresca da parte aérea (MFPA) e da raiz (MFRA) foi determinada a partir da sua pesagem em balança analítica e expressa em gramas (g).

\section{Índice de clorofila total}

A determinação do índice de clorofila total foi realizada no terço médio de das plantas com 6 repetições para cada tratamento, utilizando o aparelho clorofilômetro da marca ClorofiLOG $^{\circledR}$, modelo CFL 1030, de acordo com as instruções do fabricante (FALKER $\left.{ }^{\circledR}, 2008\right)$.

\section{Teor relativo de água da planta}

O teor relativo de água (TRA\%) foi realizado em cinco folhas do terço médio de cada tratamento de acordo com o método proposto por Rouached et al. (2013). Esse parâmetro foi determinado usando a seguinte equação (SCHONFELD et al., 1988): TRA\%= $100 \times$ (MFMS)/(MT-MS).

Onde:

TRA\% = teor relativo de água da planta;

$\mathrm{MF}=$ peso da massa fresca;

$\mathrm{MS}$ = peso da massa seca;
MT = peso da massa túrgida.

\section{Dano da membrana plasmática}

O dano da membrana plasmática (DMP) foi determinada por meio do método de Blum e Ebercon (1981) e de Silveira et al. (2001), pela quantificação de vazamento de eletrólitos através de um condutivímetro elétrico portátil microprocessado ITMCA 150P. Cinco discos de um $\mathrm{cm}$ de diâmetro foram coletados no terço médio de cada folha de cada tratamento. O ensaio foi realizado com cinco repetições biológicas.

O percentual de danos provocado na membrana plasmática (\%DM) foi calculado por meio da seguinte equação: \%DM= (L1/L2) x 100.

Onde:

DM\% = dano da membrana plasmática;

$\mathrm{L} 1$ = condutividade elétrica inicial do extrato

$\mathrm{L} 2$ = condutividade elétrica final do extrato.

\section{Análise estomática}

As lâminas foram montadas com a técnica de impressão, de acordo com Segatto et al. (2004) nas epidermes adaxial (ad) e abaxial (ab) das folhas. Para isso foram utilizadas três repetições com dez áreas de um $\mathrm{mm}^{2}$ para cada tratamento. Após a montagem das lâminas foram realizadas fotos em microscópio Olympus BX-60 e as imagens capturadas por meio do software Motic Images Plus 3.0. Foram mensurados: a densidade estomática (DE) $\left(\mathrm{mm}^{2}\right)$, o comprimento (CE) e a largura dos estômatos (LE) $(\mu \mathrm{m})$. As medições foram realizadas utilizando o software ImageJ (RASBAND, 1997).

\section{Prolina}

Os teores de prolina livre da parte aérea foram determinados de acordo com o protocolo descrito por Bates et al. (1973). As folhas (0,5 g) foram maceradas em nitrogênio líquido, adicionado $5 \mathrm{~mL}$ de ácido sulfossalicílico a $3 \%$. A mistura foi centrifugada a $12000 \mathrm{rpm}$ durante 10 min; $2 \mathrm{~mL}$ do filtrado foi misturado com $2 \mathrm{~mL}$ de ácido ninhidrina e $2 \mathrm{~mL}$ de ácido acético glacial em um tubo de ensaio. A mistura foi incubada em banho-maria por $1 \mathrm{~h}$ a $100^{\circ} \mathrm{C}$ e resfriado em temperatura ambiente. A mistura foi extraída com $4 \mathrm{~mL}$ de tolueno e a absorbância foi medida a $520 \mathrm{~nm}$. O ensaio foi realizado com cinco repetições biológicas em triplicata, e as médias 
foram calculadas usando curva padrão de prolina pré-estabelecida.

\section{Análise estatística}

Os resultados foram submetidos à análise de variância (ANOVA) $(p \leq 0,05)$ e as médias comparadas pelo teste de média de Tukey $(p \leq 0,05)$ utilizando o programa estatístico software SSPS v.22 para Windows (SPSS Inc., Chicago, IL, USA).

A distância euclidiana foi utilizada como uma métrica de dissimilaridade e agrupados pelo método Unweighted Pair Group Method with Arithmetic Averages (UPGMA). Os resultados foram apresentados em um dendrograma que caracterizou a análise de cluster (CA). A análise de cluster (CA) e a análise de componentes principais (PCA) foram realizadas a fim de discriminar as caracaterísitcas estomáticas com base nas diferentes concentrações de $\mathrm{NaCl}$. As variáveis foram realizadas usando o software " Statistica v 13.3 " (STATSOFT, 2017).

\section{Resultados e Discussão}

A irrigação diária com $\mathrm{NaCl}$ nas plantas de Z. mays everta por 15 dias afetou negativamente o crescimento das plantas, independentemente da concentração salina (Tabela 1). O comprimento da parte aérea das plantas tratadas com NaCl na concentração de 100 e 200 mM foram $34,62 \%$ e $50,26 \%$ menores que as plantas do controle, respectivamente. Sob o mesmo tratamento, o comprimento das raízes foi $15,64 \%$ e $22,27 \%$ menor em comparação com plantas não tratadas com $\mathrm{NaCl}$. Além disso, observamos que o aumento na concentração de $\mathrm{NaCl}$ resultou em uma diminuição no acúmulo de massa fresca da parte aérea e das raízes, no qual o maior declínio foi observado na maior concentração de $\mathrm{NaCl}(200 \mathrm{mM})$ (Tabela 1).

Tabela 1. Efeito das diferentes concentrações de $\mathrm{NaCl}$ no comprimento de parte aérea (CPA) ( $\left.\mathrm{cm}^{-1 a n t a}{ }^{-1}\right)$, comprimento de raiz (CRA) $\left(\mathrm{cm}\right.$ planta $\left.{ }^{-1}\right)$, massa fresca de parte aérea (MFPA) (g planta ${ }^{-1}$ ) e massa fresca de raiz (MFRA) (g planta ${ }^{-1}$ ) de Z. mays everta após 15 dias sob diferentes níveis de estresse salino.

\begin{tabular}{ccccc}
\hline Tratamento $(\mathbf{N a C l})$ & CPA & CRA & MFPA & MFRA \\
\hline $\mathbf{0 ~} \mathbf{~ M M}$ & $27,50 \pm 1,15 \mathrm{a}$ & $30,62 \pm 0,89 \mathrm{a}$ & $2,23 \pm 0,25 \mathrm{a}$ & $2,22 \pm 0,29 \mathrm{a}$ \\
$\mathbf{1 0 0} \mathbf{~ m M}$ & $17,98 \pm 1,90 \mathrm{~b}$ & $25,83 \pm 0,66 \mathrm{ab}$ & $1,06 \pm 0,10 \mathrm{~b}$ & $2,11 \pm 0,27 \mathrm{a}$ \\
$\mathbf{2 0 0} \mathbf{~ m M}$ & $13,68 \pm 0,69 \mathrm{c}$ & $23,80 \pm 1,83 \mathrm{~b}$ & $0,53 \pm 0,09 \mathrm{~b}$ & $1,93 \pm 0,18 \mathrm{a}$ \\
\hline
\end{tabular}

Média \pm desvio padrão $(n=6)$. Médias seguidas da mesma letra na coluna não diferem estatisticamente entre si pelo teste de Tukey $(p \leq 0,05)$.

0 estresse salino reduziu significativamente o TRA nas folhas em 9,76\% e $17,84 \%$ nos tratamentos 100 e 200 mM, respectivamente (Tabela 2). Por outro lado, o vazamento eletrolítico nas folhas das plantas de Z. mays everta aumentou devido ao estresse salino. Quanto maior o vazamento eletrolítico, menor a integridade da membrana plasmática e maior foi o dano causado pelo estresse salino. Observamos que a elevação máxima de vazamento eletrolítico foi de 3,86 vezes maior no tratamento com $200 \mathrm{mM}$ quando comparado ao controle (Tabela 2). O teor relativo de água e o dano da membrana celular são as primeiras características da planta que são afetadas pelo estresse salino. Isso ocorre porque o estresse hídrico ocorre frequentemente quando a planta é exposta à altas concentrações salinas no solo (AKRAMI; ARZANI, 2018).

Tabela 2. Efeito das diferentes concentrações de $\mathrm{NaCl}$ no índice de clorofila total (ICT), dano da membrana plasmática (DMP) e teor relativo de água (TRA) (\%) de Z. mays everta após 15 dias sob diferentes níveis de estresse salino.

\begin{tabular}{cccc}
\hline Tratamento (NaCl) & TRA & DMP & ICT \\
\hline $\mathbf{0 ~} \mathbf{~ M M}$ & $97,22 \pm 1,71 \mathrm{a}$ & $13,79 \pm 0,08 \mathrm{~b}$ & $15,32 \pm 4,36 \mathrm{~b}$ \\
$\mathbf{1 0 0} \mathbf{~ m M}$ & $88,73 \pm 1,54 \mathrm{~b}$ & $21,25 \pm 1,60 \mathrm{~b}$ & $29,62 \pm 3,31 \mathrm{a}$ \\
$\mathbf{2 0 0} \mathbf{~ m M}$ & $79,87 \pm 0,29 \mathrm{c}$ & $53,27 \pm 3,26 \mathrm{a}$ & $29,42 \pm 2,71 \mathrm{a}$ \\
\hline
\end{tabular}

Média \pm desvio padrão $(n=6)$. Médias seguidas da mesma letra na coluna não diferem estatisticamente entre si pelo teste de Tukey $(p \leq 0,05)$. 
A redução do crescimento inicial observado neste trabalho pode ser explicada devido aos íons $\mathrm{Na}^{+}$e $\mathrm{Cl}^{-}$presentes nos diferentes tecidos. A acumulação de íons $\mathrm{Na}^{+}$e $\mathrm{Cl}^{-}$nos tecidos foliares, por exemplo, pode resultar em fechamento estomático e/ou danos na maquinaria fotossintética que, por sua vez, resultam em menor assimilação de $\mathrm{CO}_{2}$ e consequentemente menor crescimento e acúmulo de massa fresca (JOUYBAN, 2012; ABDELGAWAD et al., 2016).

$O$ reduzido crescimento das plantas em função do estresse salino já foi observada anteriormente em diferentes trabalhos. Nazário et al. (2013) observaram que houve diminuição da massa seca da parte aérea, das raízes e área foliar ao avaliarem o desenvolvimento do milho comum PL6880 irrigado com água e $\mathrm{NaCl}$ em diferentes condutividades elétricas. A limitação do crescimento da planta é o principal efeito da salinidade, pois ocorre a imediata diminuição do conteúdo de água da planta proveniente da diminuição do potencial osmótico, devido à elevada concentração iônica, ocasionada, principalmente pelo sódio (CRUZ et al., 2003). Outros trabalhos também relataram o efeito negativo da salinidade sobre o desenvolvimento foliar e radicular na cultura do milho (SOUSA et al., 2012; SILVA et al., 2014; ABDELGAWAD et al., 2016).

Nesse estudo observamos um aumento de aproximadamente 2 vezes no índice de clorofila nas plantas submetidas ao estresse salino (100 mM e $200 \mathrm{mM}$ ), quando comparadas às plantas do controle (Tabela 2). Pandolfi et al. (2012) sugeriram que 0 estresse pode desencadear um conjunto de alterações fisiológicas que permitem às plantas resistir ao estresse salino. Como observado nesse trabalho, houve um aumento no índice de clorofila nas plantas submetidas ao estresse salino, isso pode ter ocorrido a fim de preservar o funcionamento adequado do sistema fotossintético, uma vez que, a biossíntese de clorofila e carotenóides pode aumentar em condições de estresse salino moderado (SHAH et al., 2017). Além disso, os resultados que encontramos pode ser um indicativo de que o genótipo utilizado nesse trabalho é tolerante ao $\mathrm{NaCl}$, uma vez que, um aumento no teor de clorofila sob estresse salino poderia ser um indicador bioquímico de tolerância à salinidade (ASHRAF; HARRIS, 2004; AKRAMI; ARZANI, 2018).

Ahmad et al. (2015) demonstraram que a acumulação de solutos compatíveis, como a prolina, está relacionada à tolerância a estresses abióticos, o que indica que esses osmólitos auxiliam na osmorregulação celular sob estresse salino (AHMAD et al., 2015). O conteúdo de prolina das plantas submetidas à salinidade foi significativamente aumentada em $16,7 \%$ e $53,4 \%$ nos tratamentos 100 e 200 mM, respectivamente, em relação ao controle (Figura 1). $O$ acúmulo de prolina sob estresse salino em milho e arroz já foi relatado por outros autores (CHA-UM; KIRDMANEE, 2009; ABDELGAWAD et al., 2016). Altos níveis de prolina permitem que a planta sobreviva em baixos potenciais hídricos. Além de agir como osmoprotetor, a prolina tem a capacidade de eliminar as espécies reativas de oxigênio (EROS) e proteger a célula do dano oxidativo (JOGAIAH et al., 2013; JOSEPH et al., 2015). Também é relatado que a prolina protege o mecanismo fotossintético e age como armazenamento de energia sob estresse de $\mathrm{NaCl}$ (KHAN et al., 2013, REDDY et al., 2015; AHMAD et al., 2016). 
Figura 1. Conteúdo de prolina ( $\mu \mathrm{g} \mathrm{g}^{-1} \mathrm{MF}$ ) em folhas de Z. mays everta após 15 dias sob diferentes níveis de estresse salino. (Média \pm desvio padrão). Médias seguidas da mesma letra não diferem estatisticamente entre si pelo teste de Tukey $(p \leq 0,05)$.

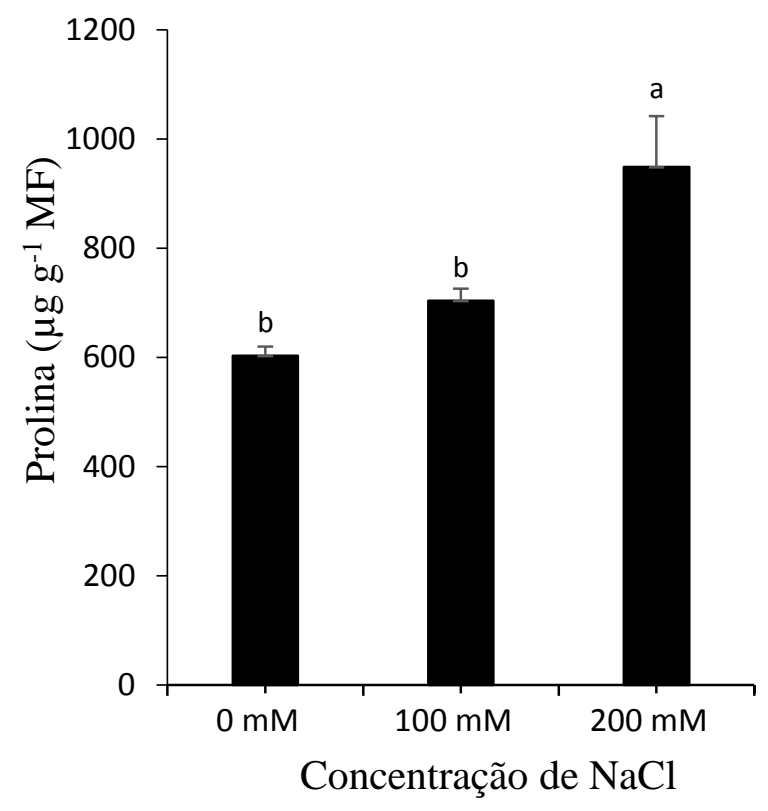

Os estômatos são importantes canais de atividade fotossintética e transpiração em plantas. Consequentemente, mudanças nas características estomáticas é uma importante resposta da planta que permite adaptações ao estresse (SHABALA et al., 2012). Nesse trabalho, observamos que o estresse salino induziu o aumento na densidade estomática (DE) das folhas de Z. mays everta na superfície abaxial, enquanto que na superfície adaxial não foi observada diferença estatística entre os tratamentos (Figura 2A e 2B). Em contraste, os estômatos se tornaram menores sob estresse salino, uma vez que, tanto o comprimento (CE) quanto a largura dos estômatos (LE) reduziram significativamente nas superfícies adaxial e abaxial (Figura 2C e 2D).
A maior frequência de estômatos encontrada em plantas estressadas poderia ser interpretada como uma estratégia de adaptação ao estresse hídrico e/ou salino, uma vez que, com o aumento na densidade estomática pode amplificar o potencial de controle sobre a taxa de perda de água, levar ao aumento da absorção de $\mathrm{CO}_{2} \mathrm{e}$ melhorar a taxa fotossintética (FRANKS; BEERLING, 2009). Além disso, a ocorrência de estômatos menores em plantas sob estresse salino em comparação com o controle, permitiriam um melhor controle da abertura e fechamento dos estômatos, uma vez que estômatos pequenos são capazes de uma resposta mais rápida à seca, em comparação com estômatos maiores (FRANKS et al., 2013). 
Figura 2. A e B Densidade estomática da superfície adaxial (DE ad) e abaxial (DE ab) da folha de Z. mays everta após 15 dias sob diferentes níveis de estresse salino. C Comprimento dos estômatos da superfície adaxial (CE ad) e abaxial (CE ab). D. Largura dos estômatos da superfície adaxial (LE ad) e abaxial (LE ab). Média \pm desvio padrão. Médias seguidas da mesma letra não diferem estatisticamente entre si pelo teste de Tukey $(p \leq 0,05)$.

A
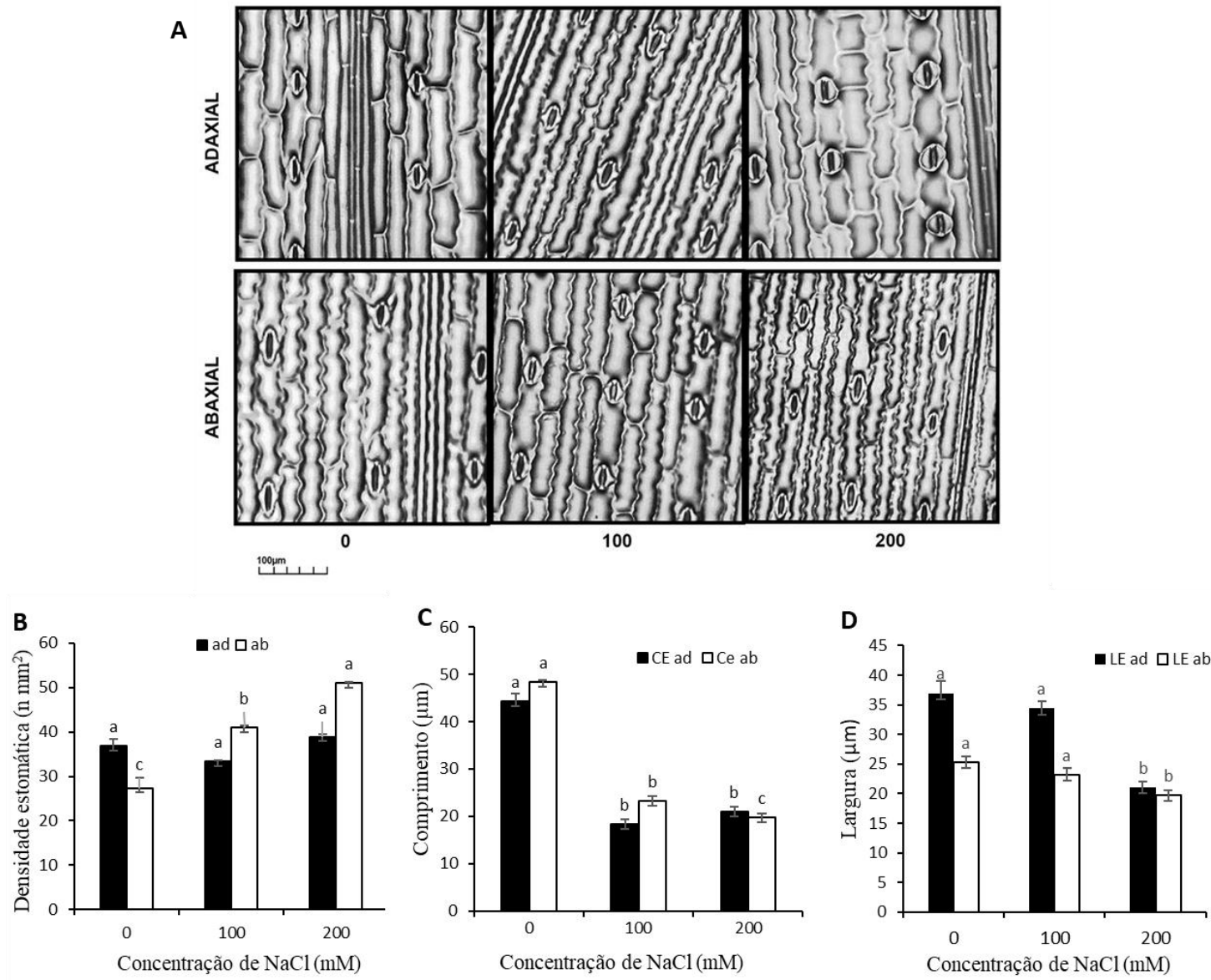

Uma análise hierárquica foi empregada com o intuito de compreender a variação morfológica ocorrida nos estômatos das plantas de milho pipoca em função do estresse salino. 0 dendrograma mostrou o agrupamento das amostras em dois clusters principais ordenados pelo nível de salinidade (Figura 3). No primeiro grupo está o controle (sem estresse). Contudo, os tratamentos com níveis de salinidade de 100 e $200 \mathrm{mM}$ de $\mathrm{NaCl}$ formaram o segundo grupo. $\mathrm{O}$ resultado do agrupamento mostrou a ordenação dos grupos pelo nível de salinidade, indicando que a salinidade influenciou as características estomáticas, provocando alteração na quantidade e nos tamanhos dos estômatos das folhas de Z. mays everta (Figuras 2 e 3). Observamos que as plantas sob estresse salino apresentaram uma alta frequência de estômatos pequenos. Folhas com estômatos pequenos e numerosos são considerados capazes de atingir baixa condutância estomática quando as condições ambientais são desfavoráveis (BARBIERI et al., 2012; DRAKE et al., 2013). 
Figura 3. Agrupamento hierárquico obtido pela análise das características dos estômatos nas folhas de $Z$. mays everta submetidos a diferentes níveis de $\mathrm{NaCl}$ com base nos dados da Figura 2 .

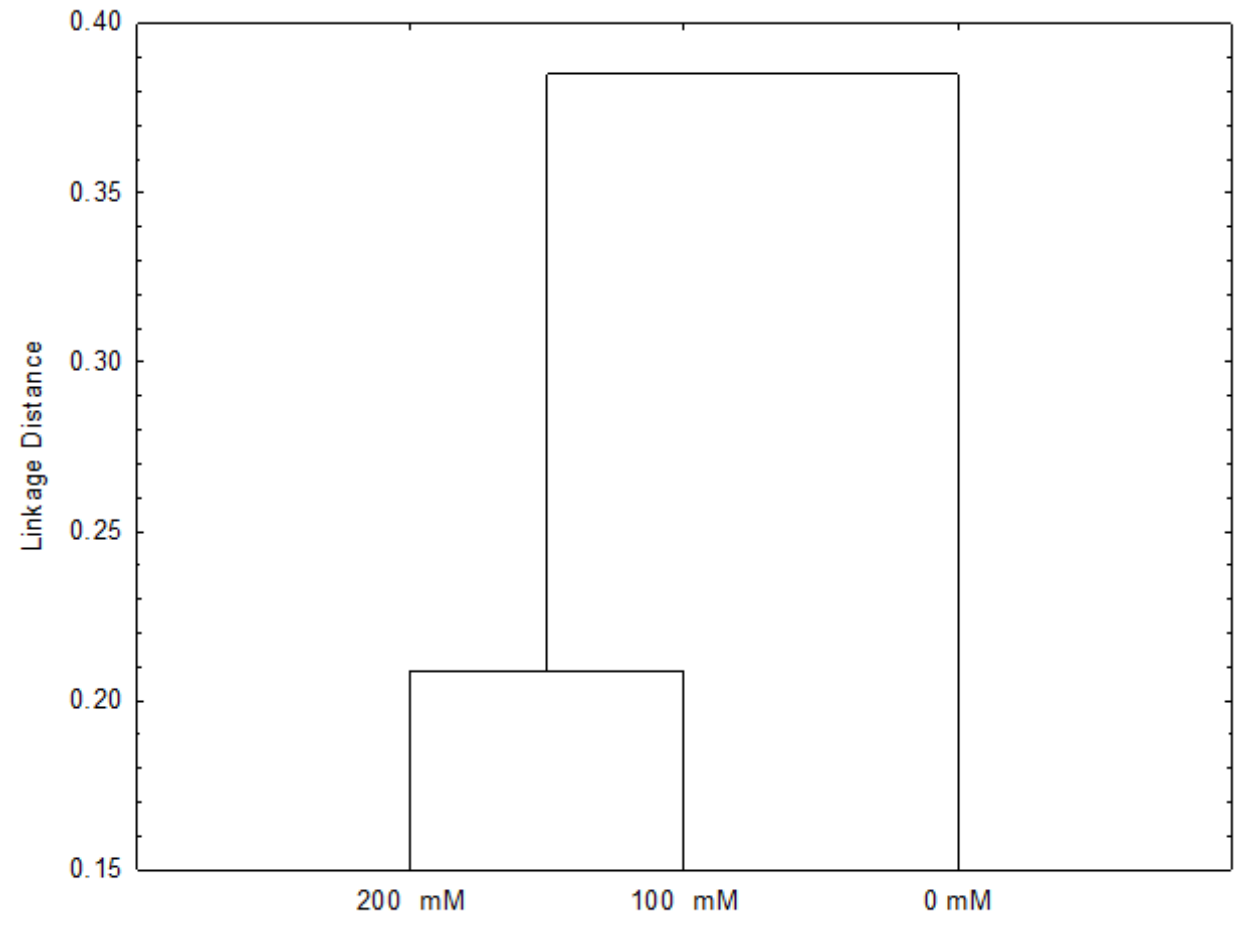

A análise dos componentes principais (PCA) permite a avaliação em conjunto das variáveis analisadas, e essa foi aplicada com o intuito de verificar a associação entre as características estomáticas e os níveis de salinidade, quando plantas de Z. mays everta foram submetidas a diferentes concentrações de $\mathrm{NaCl}$ (Figura 4). A análise de PCA apresentou uma variância total de 97,25\%, no qual as componentes principais PC1 e PC2 explicam $88,99 \%$ e $8,26 \%$ da variância total, respectivamente. Os resultados da PCA corresponderam aos obtidos na análise de agrupamento (Figuras 3 e 4). As diferentes concentrações de salinidade de 100 e 200 mM estão fortemente associados a maioria das características estomáticas avaliadas (DE, LE e CE). Essas mudanças nas características dos estômatos pode ser uma estratégia da planta para enfrentar ao estresse salino, conferindo uma aptidão para lidar com a salinidade, evitando a perda de água e sobreviver sob condições extremas. 
Figura 4. Representação biplot das características estomáticas das folhas das plantas de Z. mays everta submetidas ao estresse de $\mathrm{NaCl}$ de acordo com a análise de componentes principais (PCA). Densidade estomática adaxial (DE ad) e abaxial (DE ab); Comprimento dos estômatos adaxial (CE ad) e abaxial (CE ab); Largura dos estômatos adaxial (LE ad) e abaxial (LE ab).

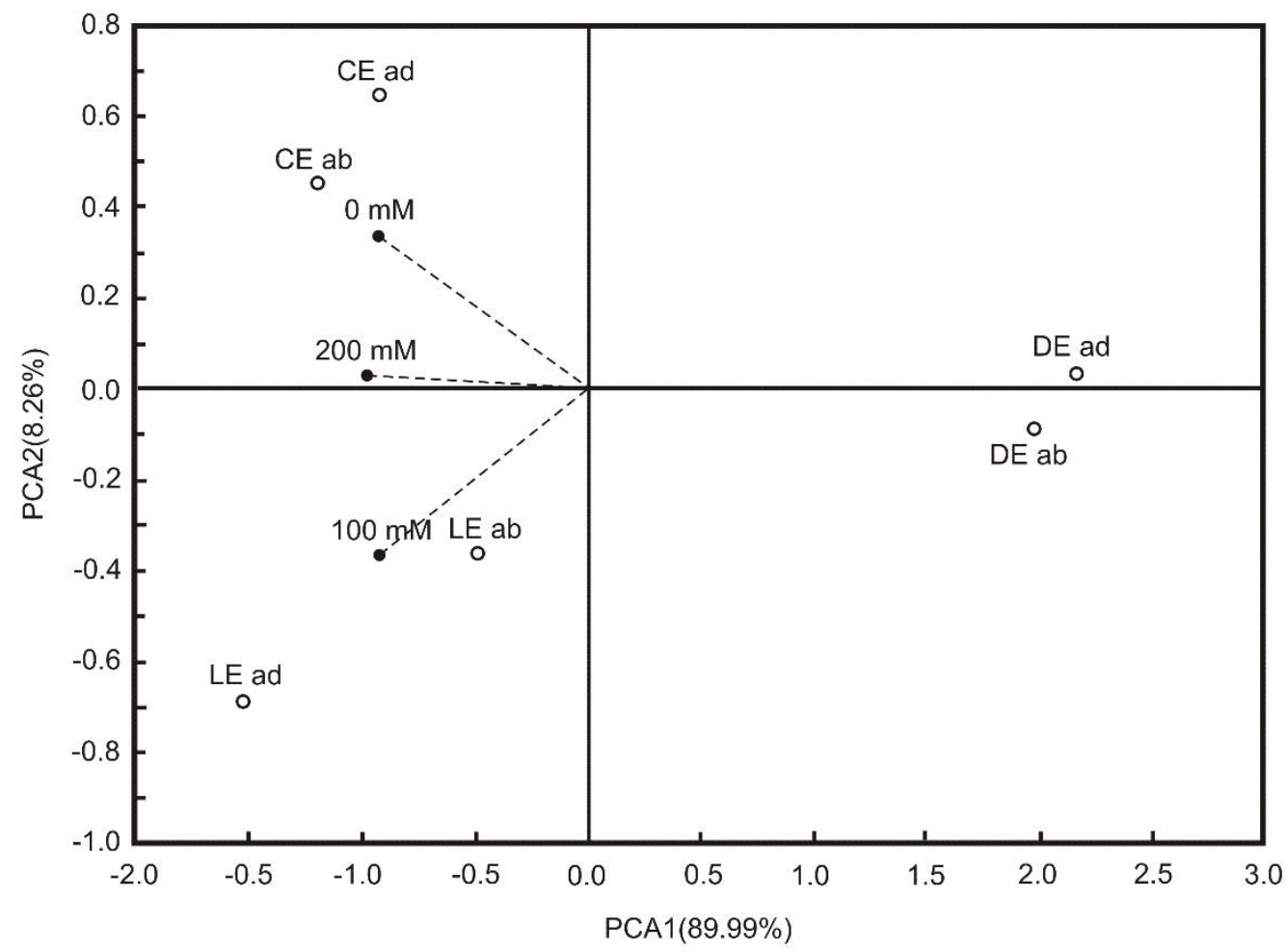

\section{Conclusão}

Em conclusão, o crescimento de plantas de Z. mays everta foi negativamente afetado pelo estresse salino, no qual foi observado uma redução do crescimento e acúmulo de biomassa de folhas e raízes. Além disso, houve um aumento do dano na membrana plasmática e consequentemente uma redução no potencial hídrico das folhas. $\mathrm{O}$ excesso de $\mathrm{NaCl}$ fez com que as plantas apresentassem um conjunto de alterações morfológicas e fisiológicas que são indicativos de mecanismos e estratégias dessas plantas para combater os efeitos da salinidade. Essas mudanças incluem o acúmulo de prolina, aumento do teor de clorofila e um aumento significativo no número de estômatos na superfície abaxial, assim como uma redução do tamanho dos estômatos. Em conjunto, essas características contribuem para uma notável tolerância à salinidade por possuir importante papel protetor contra os diferentes estresses ambientais.

\section{Referências}

ABDELGAWAD, H.; ZINTA, G.; HEGAB, M.M.; PANDEY, R.; ASARD, H.; ABUELSOUD, W.; PANDEY, R.; ASARD, H.; ABUELSOUD, W. High Salinity Induces Different Oxidative Stress and Antioxidant Responses in Maize Seedlings Organs. Frontiers in Plant Science, v.7, n.1, p. 276, 2016. https://doi.org/10.3389/fpls.2016.00276

AHMAD, P.; HASHEM, A.; ABD-ALLAH, E.F.; ALQARAWI, A. A.; JOHN, R.; EGAMBERDIEVA, D.; GUCEL, S. Role of Trichoderma harzianum in mitigating $\mathrm{NaCl}$ stress in Indian mustard (Brassica juncea $\mathrm{L}$ ) through antioxidative defense system. Frontiers in Plant Science, v.86, n.6, p. 868 ,

2015. https://doi.org/10.3389/fpls.2015.00868

AHMAD, P.; LATEF, A.A.A, HASHEM, A.; ABDALLAH, E.F.; GUCEL, S.; TRAN, L.S.P. Nitric oxide mitigates salt stress by regulating levels of osmolytes and antioxidant enzymes in chickpea. Frontiers in Plant Science, v.7, n.1, p. 1-11, 2016. https://doi.org/10.3389/fpls.2016.00347 
AKRAMI, M.; ARZANI, A. Physiological alterations due to feld salinity stress in melon (Cucumis melo L.). Acta Physiologiae Plantarum, v.40, n.91, p. 114, 2018.]

ALMEIDA, O.Á. Qualidade da água de irrigação. Versão online. Cruz das Almas, BA: Embrapa Mandioca e Fruticultura, 2010. n.1.

ASHRAF, M.; AKRAM, N.A.; AL-QURAINY, F.; FOOLAD, M.R. Drought tolerance: roles of organic osmolytes, growth regulators, and mineral nutrients. Advances in Agronomy, v.111, n.1, p. 249-296, 2011. https://doi.org/10.1016/B978-012-387689-8.00002-3

ASHRAF, M.; HARRIS, P.J.C. Potential biochemical indicators of salinity tolerance in plants. Plant Science, v.166, n.1, p.3-16, 2004. https://doi.org/10.1016/j.plantsci.2003.10.024

BARBIERI, G.; VALLONE, S.; ORSINI, F.; PARADISO, R.; DE PASCALE, S.; NEGRE-ZAKHAROV, F.; MAGGIO, A. Stomatal density and metabolic determinants mediate salt stress adaptation and water use efficiency in basil (Ocimum basilicum L.). Journal of Plant Physiology, v.169, n.17, p.1737-1746, 2012. https://doi.org/10.1016/j.jplph.2012.07.001

BATES, L.S.; WALDERN, R.P.; TEARE, I.D. Rapid determination of free proline for water stress studies. Plant and Soil, The Hague, v. 39, n.1, p. 205-07,

1973. https://doi.org/10.1007/BF00018060

BLUM, A.; EBERCON, A. Cell membrane stability as a measure of drought and heat tolerance in wheat. Crop Science, v.21, n.1, p. 43-47, 1981. https://doi.org/10.2135/cropsci1981.0011183X0 $\underline{02100010013 x}$

CHA-UM, S; KIRDMANEE, C. Effect of salt stress on proline accumulation, photosynthetic ability and growth characters in two maize cultivars. Pakistan Journal of Botany, v.41, n.1, p. 87-98, 2009.

CRUZ, J.L.; PELACANI, C.R.; SOARES FILHO, W.D.S.; CASTRO NETO, M.D.; COELHO, E.F.; DIAS, A.T.; PAES, R.A. Produção e partição de matéria seca e abertura estomática do limoeiro 'Cravo' submetido a estresse salino. Revista Brasileira de Fruticultura, v. 25, n. 3, p. 528-531, 2003.
https://doi.org/10.1590/S0100-

$\underline{29452003000300042}$

DAWANDE, R. Popcorn Market by Type (Microwave Popcorn and Ready-to-eat Popcorn) and End User (Household and Commercial) Global Opportunity Analysis and Industry Forecast, 2017-2023. Allied Market Research, 2018. Disponível em: https://www.alliedmarketresearch.com/popcornmarket. Acesso em: 12 fev. 2019.

DOUPIS, G.; BOSABALIDIS, A.M.; PATACAS, A. Comparative effects of water deficit and enhanced UV-B radiation on photosynthetic capacity and leaf anatomy traits of two grapevine (Vitis vinifera L.) cultivars. Theoretical and Experimental Plant Physiology, v.28, n.1, p. 131141, 2016.

DRAKE, P.L.; FROEND, R.H.; FRANKS, P.J. Smaller, faster stomata: scaling of stomatal size, rate of response, and stomatal conductance. Journal of Experimental Botany, v.64, n.1, p. 495-505, 2013. https://doi.org/10.1093/jxb/ers347

ESTEVES, B.S.; SUZUKI, M.S. Efeito da salinidade sobre as plantas. Oecologia Brasiliensis, v.12, n.4, p. 662-679, 2008.

FRANKS, P.J.; BEERLING, D.J. Maximum leaf conductance driven by $\mathrm{CO}_{2}$ effects on stomatal size and density over geologic time. Proceedings of the National Academy of Sciences, v.106, n.1, p. 10343-10347, 2009. https://doi.org/10.1073/pnas.0904209106

FRANKS, F. Water: A comprehensive Treatise. Aqueous Solutions of Amphiphiles and Macromolecules, v.4, 2013.

FALKER, A.AG. LTDA. Manual do medidor eletrônico de clorofila ClorofiLOG CFL 1030. Porto Alegre, 2008.

HOAGLAND, D.R.; ARNON, D.I. The water-culture method for growing plants without soil. Circular California Agricultural Experiment Station, v.347, n.2, 1950.

JIANG, C.; ZU, C.; LU, D.; ZHENG, Q.; SHEN, J.; WANG, H.; LI, D. Effect of exogenous selenium supply on photosynthesis, $\mathrm{Na}+$ accumulation and antioxidative capacity of maize (Zea mays L.) 
under salinity stress. Scientific Reports, v.7, n.1, p. 42039, 2017. https://doi.org/10.1038/srep42039

JOUYBAN, Z. The effects of salt stress on plant growth. Technical Journal of Engineering and Applied Sciences, v.2, n.1, p. 7-10, 2012.

JOSEPH, E.A.; RADHAKRISHNAN, V.V.; MOHANAN, K.V. A Study on the Accumulation of Proline- An Osmoprotectant Amino Acid under Salt Stress in Some Native Rice Cultivars of North Kerala, India . Universal Journal of Agricultural Research, v.3, n.1, p. 15-22, 2015.

KHAN, M.I.R.; IQBAL, N.; MASOOD, A.; et al. Salicylic acid alleviates adverse effects of heat stress on photosynthesis through changes in proline production and ethylene formation. Plant Signaling and Behavior, v.8, n.11, p. 26374, 2013. https://doi.org/10.4161/psb.26374

KONUŞKAN, Ö.; GÖZÜBENLI, H.; ATIŞ, I.; ATAK, M. Effects of Salinity Stress on Emergence and Seedling Growth Parameters of Some Maize Genotypes (Zea mays L.). Turkish Journal of Agriculture-Food Science and Technology, v.5, n.12, p.1668-1672, 2017. https://doi.org/10.24925/turjaf.v5i12.1668-

\section{$\underline{1672.1664}$}

MARIJUAN, M.P.; BOSCH, S.M. Ecophysiology of invasive plants: osmotic adjustment and antioxidants. Trends in Plant Science, v.18, n.12, p.660-666, 2013. https://doi.org/10.1016/j.tplants.2013.08.006

MIRANDA, D. S.; DA SILVA, R.R.; TANAMATI, A.A.C.; CESTARI, L.A.; MADRONA, G.S.; SCAPIM, M.R. Avaliação da qualidade do milho-pipoca. Revista Tecnológica (Edição Especial V Simpósio de Engenharia, Ciência e Tecnologia de Alimentos), Maringá, v.1, n.1, p. 13-20, 2011.

MOLAZEM, D.; AZIMI, J. Morpho-Physiological Characterization in Eight Varieties of Maize (Zea mays L.) under Soil Salinity. Polish Journal of Environmental Studies, v.24, n.6, 2015. https://doi.org/10.15244/pjoes/59400

MORALES, M.A.; OLMOS, E.; TORRECILLAS, A.; SÁNCHEZ-BLANCO, M.J.; ALARCON, J.J. Differences in water relations, leaf ion accumulation and excretion rates between cultivated and wild species of Limonium sp. grown in conditions of saline stress. Flora, v.196, n.5, p.345-352,

2001. https://doi.org/10.1016/S0367-2530(17)30070-1

MUNNS, R. Genes and salt tolerance: bringing them together. New Phytologist, v. 167, n.1, p. 645-663, 2005. https://doi.org/10.1111/j.14698137.2005.01487.x

MUNNS, R.; GILLIHAM, M. Salinity tolerance of crops-what is the cost?. New phytologist, v.208, n.3, p.668-673, 2015. https://doi.org/10.1111/nph.13519

NAZÁRIO, A.A.; BESTETE, L.O.; GARCIA, G.O.; REIS, E.F.; CECÍLIO, R.A. Desenvolvimento e produção do milho irrigado com água de diferentes condutividades elétricas. Engenharia Ambiental, Espírito Santo do Pinhal, v.10, n.2, p. 117-130, 2013.

NEVES, L.A.S.; SPAT C. Concentração de clorofila e de prolina em genótipos de arroz submetidos à salinidade. Revista Unimontes Científica, Montes Claros, v.15, n.1, 2013.

OLIVEIRA, F.D.A.; DE MEDEIROS, J.F.; DE OLIVEIRA, M.K.; LIMA, C.J.D.S.; DE ALMEIDA JÚNIOR, A.B.; AMÂNCIO, M.D.G. Desenvolvimento inicial do milho-pipoca irrigado com água de diferentes níveis de salinidade. Revista Brasileira de Ciências Agrárias, v. 04, n.02, p. 149-155, 2009. https://doi.org/10.5039/agraria.v4i2a5

OLIVEIRA, F.J.V.; DE CARVALHO, R.N.; SOARES, T.F.; NETO, A.F.; DOS ANJOS, J.B.,; DE SOUZA, A.V. V. Avaliação de Diferentes Dosagens de Esterco Caprino na Cultura Do Milho Pipoca (Zea Mays L.) Na Região do Submédio do Vale do São Francisco. Revista Científica, v.6, n.2, p. 323-331, 2016.

ORTEGA, I.S. Maíz I (Zea mays). Reduca (Biología). Serie Botánica, v.7, n.22, p.151-171, 2014.

PANDOLFI, C.; MANCUSOA, S.; SHABALAb, S. Physiology of acclimation to salinity stress in pea (Pisum sativum). Environmental and Experimental Botany, v.84, n.1, p. 44-51, 2012. https://doi.org/10.1016/i.envexpbot.2012.04.015

PERVEEN, S.; NAZIR, M. Proline treatment induces salt stress tolerance in maize (Zea Mays 
L. CV. Safaid Afgoi). Pakistan Journal of Botany, v.50, n.4, p.1265-1271, 2018.

RASBAND, W.S. ImageJ, U. S. National Institutes of Health. Bethesda, Maryland, 1997. Disponível em: https://imagej.nih.gov/ij/

REDDY, P.S.; JOGESWAR, G.; RASINENI, G.K.; MAHESWARI, M.; REDDY, A.R.; VARSHNEY, R.K.; KISHOR, P.K. Proline over-accumulation alleviates salt stress and protects photosynthetic and antioxidant enzyme activities in transgenic sorghum (Sorghum bicolor (L.) Moench). Plant Physiology and Biochemistry, v.94, n.1, p. 104113, 2015. https://doi.org/10.1016/i.plaphy.2015.05.014

SCHONFELD, M.A.; JOHNSON, R.C; CARVER, B.F. Water realtions in winter wheat as drought resistence indicators. Crops Science, v.28, n.1, p. 521-531, 1988.

SHABALA, L.; MACKAY, A.; TIAN, Y.; JACOBSEN, S.E.; ZHOU, D.; SHABALA, S. Oxidative stress protection and stomatal patterning as components of salinity tolerance mechanism in quinoa (Chenopodium quinoa). Physiologia Plantarum, v.146, n.1, p. 26-38. 2012. https://doi.org/10.1111/j.1399-

3054.2012.01599.x

SHAH, S.H.; HOUBORG, R.; MCCABE, M.F. Response of chorophyll, carotenoid andSPAD-502 meansurement to salinity and nutriente stress in wheat (Triticum aestivum L.). Agronomy, v.7, n.61, 2017.

SILVA, J.L.A.; MEDEIROS, J.F.; ALVES, S.S.V.; et al. Uso de águas salinas como alternativa na irrigação e produção de forragem no semiárido nordestino. Revista Brasileira de Engenharia Agrícola e Ambiental, v.18, n.1, p. S66-S72, 2014. https://doi.org/10.1590/1807-

1929/agriambi.v18nsupps66-s72

SILVA, F.D.; FERREIRA, A.A.; LIMA, D.C.; MEDEIROS, A.D.; MARACAJÁ, P.B.; MEDEIROS, A. D. Estresse salino e adubação mineral na composição nutricional da cultura do milho. Revista Brasileira de Gestão Ambiental, v.11, n.1, p. 76-83, 2017.

SILVEIRA, J.A.G.; MELO, A.R.B.; VIÉGAS, R.A.; OLIVEIRA, J.T.A. Salt-induced effects on the nitrogen assimilation related to growth in cowpea plants. Environmental and Experimental Botany, Memphis, v.46, n.2, p. 171-179, 2001. https://doi.org/10.1016/S0098-8472(01)00095-8

SOUSA, G.G.; MARINHO, A.B.; ALBUQUERQUE, A.H.P.; DE ARAÚJO VIANA, T.V.; DE AZEVEDO, B.M. Crescimento inicial do milho sob diferentes concentrações de biofertilizante bovino irrigado com águas salinas. Revista Ciência Agronômica, v.43, n.2, p. 237-245, 2012. https://doi.org/10.1590/S1806$\underline{66902012000200005}$

SOUZA, M.W.L.; CUNHA, R.C.; DE ALMEIDA COSTA, P.A.; DE MOURA, I.N.B.M.; BEZERRA, F.M.S.; LIMA, L. A. Desenvolvimento inicial de milho doce e milho pipoca sob estresse salino. Agropecuária Científica no Semi-Árido, v.10, n.3, p.65-72, 2014.

STATSOFT. Electronic statistics textbook. Tulsa: StatSoft, 2017. 